\title{
Unsere Beratungsschwerpunkte
}

Praxisgründung

- Standortanalysen

- Praxisplanung und -einrichtung

- Gruppenpraxenberatung

- Evaluation von Praxisadministrationssoftware

- Rechtsberatung

Praxisführung

- Gemeinsamer Einkauf für Ärztinnen und Ärzte

- Ärztedrucksachen

- Praxislabor

- Röntgenanlageberatung

Praxisübergabe / -übernahme

- Nachfolgeplanung und -regelung

- Unternehmenswertberechnungen / Praxisverkauf

- Praxisvermittlung

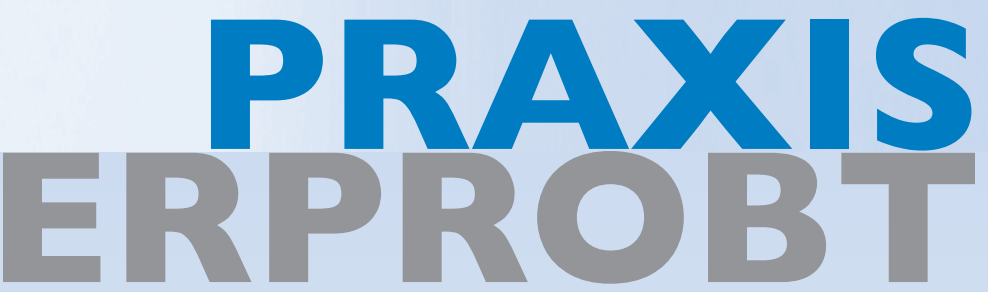

Treuhand

- Finanz- und Rechnungswesen

- Analysen

- Steuern

Vermögen - Vorsorge - Versicherungen

- Versicherungslösungen

- Umfassende Vorsorge- und Finanzplanung

- Neutrale Vermögensverwaltung

- Pensionsplanung

Seminarangebot

- Seminare zu Themen wie Praxiseröffnung/-übernahme, Praxisübergabe, Finanz- und Steuerplanung, EDV-Workshop und viele andere

Praxis- und Stellenvermittlung

- Insertionsplattform in der Ärztezeitung / Stellen- und Praxisofferten sowie Gesuche

- Stellenmarkt unter www.fmhjob.ch

- Praxismarkt unter www.fmhprax.ch

Factoring

- Echtes Factoring - Ankauf der Honorarforderungen

- Administrationsentlastung im Debitorenmanagement

- Liquiditätssicherung durch Sofortauszahlung der Honorarbeträge

- Delkredere-Schutz

Inkasso

- Bonitätsprüfung (online via my.inkas)

- Vorrechtliches und rechtliches Inkasso

- Verlustscheininkasso

\section{乌̈FH SERVICES}

